\title{
La necesidad de la revitalización sindical: una oportunidad para otras propuestas organizativas
}

\section{David Moral-Martín, Ignasi Brunet i lcart}

RESUMEN: Este artículo tiene por objetivo analizar la emergencia de Nuevos Movimientos Sindicales (NNMMSS) vinculándola a la oportunidad de revitalización que puede suponer para las contemporáneas centrales sindicales mayoritarias, hijas del taylorismo-fordismo. Para ello, nos centramos en el análisis de sus aportaciones. A nivel teórico, estudiamos el alcance de las críticas vertidas al actual modelo de representación salarial, resaltando la necesidad de asumir la teoría de la oferta y la importancia de los factores internos para afrontar la citada revitalización. Y a nivel práctico, señalamos su apuesta por la horizontalidad en las tomas de decisiones de colectivos con menor representación histórica y por prácticas de afiliación múltiple que cuestionan tanto el reparto del poder como los límites de la negociación colectiva. Estas son las principales conclusiones extraídas de un estudio llevado a cabo en Cataluña. Cualitativamente nos hemos basado en la realización de entrevistas semiestructuradas a representantes cualificados de sindicatos mayoritarios y minoritarios, de NNMMSS y miembros de asociaciones empresariales y expertos académicos, junto al análisis crítico de la literatura científica vinculada.

PALABRAS CLAVE: Sindicatos, revitalización, representación, afiliación, participación.

CLAVES ECONLIT: J51, K31.

Cómo citar este artículo/How to cite this article: MORAL-MARTÍN, D. \& BRUNET, I. (2021): "La necesidad de la revitalización sindical: una oportunidad para otras propuestas organizativas", CIRIEC-España, Revista de Economía Pública, Social y Cooperativa, 101, 227-254. DOI: 10.7203/CIRIEC-E.101.16542.

Correspondencia: David Moral-Martín, Universidad Rovira i Virgili, josedavid.moral@urv.cat; Ignasi Brunet i Icart, Universidad Rovira i Virgili, ignasi.brunet@urv.cat. 


\section{Expanded abstract}

\section{The Need for Trade Union Revitalisation: An Opportunity for Other Organisational Proposals}

\section{Purpose}

The aim of this article is to analyse the emergence of a series of wage salarial organizations which we have called New Union Movements (NUMs). The reason for this is that their creation is clearly relevant to the study and understanding of the contemporary revitalization of certain national trade union centres, which are the result of Taylorism and Fordism and who are tackling current important challenges. For this reason we focus on the contributions made by NUMs. Specifically, we study the criticisms levelled at the current model of wage representation based almost exclusively on supply-side theory, because their presence leaves an unanswered question: what are their organizational responsibilities? The creation of NUMs and their union actions seem to answer it.

Our hypothesis, therefore, is that although the aforementioned theory exclusively blames the current conditions brought about by globalization and neoliberalism for the supposed loss of union influence, it does not fully explain the current situation of the national trade union centres. It is for this reason that the existence of NUMs seems to incorporate demand connected to the activities of national trade union centres.

\section{Approach}

This qualitative study has been conducted in Catalonia (Spain). To analyse the situation, we have used a qualitative and transversal methodology involving semi-structured interviews with qualified representatives of major and minor unions, NUMs and members of business associations and academic experts specifically selected for their capacity to provide appropriate, detailed, in-depth and relevant information regarding the union movement. To improve the approach, this study has focused on two principal aspects: 1) the question of assemblies as an alternative means of internal organization, and 2) the NUMs' strategy of multiple affiliation.

A consensus seems to have been reached between academics who study union organisations and what used to be referred to as the workers' movement regarding the extreme difficulty facing the unions, which have on too many occasions been described as organizations from an earlier time who are of no interest to current workers. However, the appearance of NUMs has led to the need to rethink certain, long accepted assertions made about the union movement, such as their decline. 
This study highlights the inconsistency between those who say that unions have disappeared and the reality that they have not, given that since at least the start of the 21st century new formulas have been emerging based on the main aspects of these workers' organizations, namely their capacity to form around certain working conditions that justify collective representation, and their capacity to reclaim and organize the conflict caused by different interests.

Therefore, the creation of NUMs, at least those linked to the services sector that we have studied, fundamentally questions traditionally pessimistic studies regarding the future of the union movement. In parallel, they question very prevalent aspects of the national trade union centres, which should challenge them to start a process of reflection regarding how they should orient their union activities to bring together the various different groups who have for one reason or another preferred to organize themselves separately and how they can appeal to minority unions and to those who have affiliated themselves with the large unions.

\section{Finding}

We have found that the appearance of these new organizations has questioned the discourse that their disappearance is inevitable and at the same time has revitalized the debate regarding Labour Revitalization Studies (LRS), these being "strategies that can broaden perspectives and reverse the decline" (Turner, 2004: 2). Specifically, we analyse two union behaviours that implement three of the strategies for revitalizing the union movement (Frege and Kelly, 2006), which are linked to the vision of syndicalism and unitary representation. On an internal level, we point to the existence of certain criticisms regarding forms of participation and representation, given that these forms continue to marginalise those gender, generational and ethnic groups that have historically been underrepresented, an issue that is clearly linked to the question of organizing, the need to recruit members and increase union presence, which is the purpose for which they were created. This is the situation that the NUMs seek to correct by establishing horizontal systems in decision taking processes.

Externally, attempts have been made to overcome the lack of intervention through multiple affiliation, which is closely related to collective bargaining, and participation in negotiations at both sectoral and business levels. Finally, we include political action as the nexus that unites both actions in their efforts to improve working conditions by turning to employment law.

Therefore, this text makes two contributions. In terms of internal aspects, we have focused on participation, a matter of great criticism among the NUMs studied. This argument questions the strategy followed by the unions since at least the 1990s, when they turned away from conflict towards negotiation, which in turn possibly gave excessive power to union leaders, who benefited from supply-side theory. In this regard, the NUMs' complaints regarding their limited and relatively unimportant participation have placed a new element at the heart of the debate regarding the loss of union power: how should they respond to this situation?

In terms of external aspects we look at negotiation within the ambit of business. Given the system of labour representation in Spain, which is designed to give greater representation to unions with more members, these NUMs seem to share a common strategy in order to be able 
to participate, such as multiple affiliation, which enables them to combine their activities in the association with their participation in unions, thus ensuring that they are present in ambits that are usually off limits due to their limited representativeness.

\section{Limitations}

Unfortunately, given the current progress of our studies, we are not able to evaluate whether their working conditions have improved, despite the indicators that suggest a tendency towards improvement, as seems to be indicated by a series of laws that have been named after those they affect, such as the Riders' Law (food delivery riders) and Kellys Law (housemaids).

\section{Practical Conclusions}

The appearance of NUMs has been a significant change in the trade union movement insofar as they have questioned various behaviours which, linked to supply-side theory, have been shown to have caused the current situation. We refer to the importance of participation among central workers and to the excessive institutionalization of the most representative unions and the configuration and limits of collective bargaining.

In the face of all of these situations, the NUMs have managed to articulate a set of actions similar to those listed in the LRS, and they are based on two different but closely related ambits. Internally, the appearance of assemblies as a form of participation that helps to identify errors and deviations by basing its decision-making sovereignty on its affiliates as a whole, connected to the revitalizing strategy of organizing and political action, which can be in person for some, such as the contract staff at Movistar; at a distance for others, such as Kellys (housemaids); and at business level (cooperatives) for a small group of food delivery workers (Riders).

In terms of the external aspects, we point to multiple affiliation as the best tactic for participating in representation in a workplace that seems to be aimed towards traditional unions, linked to renovation through negotiation. The merit of their presence is equivalent to the astuteness of their flexibility to be able to join a closed system and to the use of lesser represented unions in their sector to organize union elections. Their merit also lies in the use of national trade union centres to participate in different workplaces, together with the use of an alternative union to organize people who sell their labour to others.

Finally, the two NUM behaviours that we have analysed have given rise to a means of negotiating through legislation, which we have included in the strategy of political action, because it is used by these groups, as is demonstrated by popular names given to the resulting laws ("Ley Kellys and Ley Riders") and which must be added to all attempts to participate in collective bargaining (at sectoral level and above all business level), and to regard them as another attempt to defend and improve their respective employment conditions.

Keywords: Unions, revitalization, representation, membership, participation. 


\section{Introducción}

El actual contexto del sindicalismo a nivel mundial, pero sobre todo europeo, evidencia una situación en la que diferentes centrales sindicales nacionales continúan tratando de reinventarse (Alòs, 2017), en especial tras la crisis económica de 2008 descrita como un periodo especialmente difícil para el organizacionismo laboral por Gumbrell-McCormick y Hyman (2013). Esta situación ha proyectado una imagen derrotista del colectivismo salarial, propiciando que su actual estudio sea abordado desde una perspectiva negativa: la del denominado declive (Calleja Jiménez, 2017). Este consenso desafortunadamente se viene arrastrando desde hace varias décadas, y ello a pesar de la inexistencia de datos definitivos que lo confirmen.

Esta falta de corroboración empírica se ha venido supliendo con determinadas explicaciones que ahondan en esta situación tan particular. De ahí que se entienda perfectamente que, precisamente por esta carencia, no se haya logrado consensuar una fecha concreta sobre el origen del citado comportamiento sindical. Barranco y Molina (2014) lo han ubicado a comienzos de los años 70 del siglo XX. Por su parte, Bryson et al. (2011) han señalado la existencia de un amplio consenso situándolo, al menos, a partir de la década de 1980. Sin embargo, existen razones que nos permiten comprender por qué se ha producido una auténtica revisión de la figura del sindicalismo entre finales de los años 80 y comienzos de la crisis económica, argumentos que Ezquerra et al. (2015) han vinculado al periodo denominado de globalización neoliberal.

Esta globalización también, y paradójicamente, ha sido utilizada por el sindicalismo como respuesta oficial para explicar su pérdida real de poder social e institucional, al basar prácticamente toda su explicación en la teoría de la demanda (Beneyto Calatayud, 2018). Para Ezquerra et al. (2015: 25), su hegemonización ha favorecido la intensificación de la "ofensiva contra los sindicatos a fin de imponer fuertes reducciones a la protección del empleo y abrir el sector público a las ganancias empresariales". Köhler y Calleja Jiménez (2015: 240), por su parte, también defienden parcialmente esta estrategia reduccionista, al asegurar que "una de las víctimas más prominentes de esta gestión neoliberal de la crisis ha sido el poder institucional de los sindicatos". Esta situación deja una pregunta por responder: ¿cuáles son sus responsabilidades organizativas? La creación de Nuevos Movimientos Sindicales (NNMMSS) y sus acciones sindicales parecen responderla. Ambos hechos señalan la necesidad de incorporar la teoría de la oferta para completar la explicación sobre la actual situación de los sindicatos mayoritarios y posibilitar su renovación, habida cuenta de que sus funciones de redistribución y cohesión social son "cada vez más importantes" (Calleja Jiménez, 2017: 293).

Precisamente este es nuestro interés a nivel español y en concreto catalán. Para contextualizarlo acudimos a sus datos de afiliación, a los que posteriormente nos referiremos. Estos han sido utilizados, por los NNMMSS y otros sindicatos minoritarios, para construir una imagen del sindicato como una entidad burocrática y ensimismada en sus propios intereses y, por lo tanto, sin posibilidad ninguna de transformarse; gobernada por un colectivo alejado, por género, generación y estatus contractual, de una gran cantidad de trabajadores que han visto empeorar sus condiciones salariales y laborales a lo largo de esta recesión. En este sentido, 
resulta interesante conocer qué actuaciones de revitalización sindical han llevado a cabo los NNMMSS para establecer diferencias.

Para ello analizamos dos de sus comportamientos sindicales que desarrollan tres de las estrategias de la revitalización sindical (Frege y Kelly, 2006), que están vinculadas a una serie de preguntas englobadas en el bloque de análisis de la situación, concretamente en lo referido a la visión del sindicalismo y a la representación unitaria. A nivel interno, señalamos la existencia de ciertas críticas hacia las formas de participación y de representación, ya que continúan manteniendo alejados a colectivos que históricamente han tenido una menor representación (de género, generacional y étnica), claramente vinculada a la cuestión del organizing y su necesidad de ganar en militancia y en presencia, para lo cual se crearon. Esta situación trata de ser corregida por los NNMMSS al establecer sistemas horizontales en los procesos de toma de decisiones. A nivel externo, la falta de intervención se ha tratado de superar practicando la afiliación múltiple, íntimamente relacionada con la collective bargaining, y la participación en negociaciones tanto a nivel sectorial como principalmente empresarial. Finalmente, incorporamos la political action como el punto de unión de ambas acciones en su intento por mejorar sus condiciones de trabajo mediante el recurso a la legislación laboral.

\section{Marco analítico}

A mediados de 1990, Däubler (1994: 75) expuso la interpretación cuantitativa del declive sindical -"su número de afiliados lleva años estancado o incluso ha retrocedido"-, lo que provocó un consenso incontestable. Recopilando informaciones similares, Antentas (2008: 37) resumió que "desde hace ya bastantes años es común utilizar el término 'crisis' para referirse a la situación de los sindicatos". Recientemente, y para Europa, Gumbrel-MacCormick y Hyman (2013: 8), lo han certificado al cuantificar "una caída, entre 1990 y 2008, de millones de afiliados a los sindicatos". En la actualidad, García Escribano y Millán Jiménez (2017: 109) describen la situación del declive: "a partir de los años noventa, se comienza a hablar de la crisis del sindicalismo, de la disminución del número de afiliados, de su dificultad para agregar los intereses diversos de una heterogénea clase trabajadora, de su incapacidad para hacer un diagnóstico acertado de la situación, en definitiva, de la merma de su capacidad de presión y poder".

Pese a este consenso, más o menos amplio, existen numerosos trabajos que han demostrado que esta afirmación pecaba de inexactitud, ya que el comportamiento sindical no ha sido tan homogéneo como para poder resumirlo en una fórmula, positiva o negativa (Moral y Brunet i Icart, 2018). Es por ello por lo que las interpretaciones del declive han sido rebatidas entre otros por Ebbinghaus y Visser (1999), por Bernaciack et al. (2015) y más recientemente por Vandaele (2019), quienes han señalado la existencia de aumentos afiliativos en algunos países europeos, sobre todo entre los que conforman el modelo mediterráneo (Brunet i Icart et al., 2019), lo que ha sido corroborado por Beneyto Calatayud (2018) y por Jódar et al. (2017) para el caso español. Por todos estos argumentos no se puede hablar objetivamente de la existencia de un declive generalizado. 
Al calor de estas aproximaciones, se produjeron nuevas orientaciones metodológicas e interpretativas vinculadas a la década de 1990. Beneyto Calatayud (2017) señala la emergencia de una corriente de estudios académicos basados en la idea de la renovación sindical, conocidos como Labour Revitalization Studies (LRS) y descritos por Turner (2004: 2) como "estrategias que puedan ampliar la perspectiva y revertir el declive". Su origen cabe situarlo entre los países anglosajones y se extendieron posteriormente a otros como Alemania (Doellgast y Greer, 2007) y Francia (Béroud y Bouffartigue, 2009). En España destaca el trabajo de Martínez Lucio (1998) y, más recientemente, de García Calavia y Rigby (2016), entre otros.

En este sentido, y esperando los resultados de su implantación, Behrens et al. (2004: 2124) han señalado una nueva forma de examinar la citada renovación, a través del análisis de la afiliación, el poder económico y de la negociación y la vitalidad institucional. Estas dimensiones, que han sido traducidas en determinadas estrategias por Frege y Kelly (2006: 32-35), son descritas a continuación. Todas ellas han conformado la clasificación de una serie de actuaciones concretas por implantar que recientemente han sido enumeradas por Beneyto Calatayud (2017: 16): "reclutamiento, reestructuración organizativa, negociación, participación institucional, alianzas y comunicación". Se trata de un conjunto de propuestas que parten de analizar los factores externos y evaluar los de origen interno de cara a superar la histórica, y relativa, pérdida afiliativa, bajo el claro objetivo de ganar en presencia (afiliativa) e influencia (institucional y social).

Frege y Kelly (2006: 32-35) han descrito estas seis estrategias. Para su presentación las ordenamos en función de su uso en este texto. Comenzamos con las que utilizamos y posteriormente lo haremos con las que no son objeto de este trabajo. Los diferentes NNMMSS que estudiamos han puesto en práctica las siguientes tres estrategias de revitalización, asociadas a dos de sus citados comportamientos. El primero, la apuesta por la participación horizontal se encuentra vinculada, por un lado, a la del organizing, descrita como el intento por recuperar o incrementar (como es nuestro caso) su propia militancia (para ello, y como paso previo, en lugar de afiliarse a una de las centrales sindicales conocidas, optaron por la creación de organizaciones a las que las personas se pudiesen incorporar en un primer lugar, sin que sean estrictamente sindicatos, para su movilización, además de tratar de fortalecer su representación en el centro de trabajo; por este motivo entre otras razones apostaron por el diseño asambleario); por otro, se optó por la political action, o el intento por influir sobre los gobiernos para obtener una favorable legislación laboral, tal como han hecho tanto las camareras de piso como los riders, al comprobar las dificultades de la negociación colectiva sectorial y de empresa. Esta actuación se sitúa como gozne entre ambas actuaciones sindicales, ya que para ello se necesita de una organización formal y que pretenda negociar, lo que las vincula y refuerza por la especial habilidad de estos NNMMSS en su intento por influir sobre la realidad laboral contemporánea.

El segundo comportamiento, la táctica de la afiliación múltiple o su laxitud ideológica de pertenencia, se encuentra íntimamente vinculado a la estrategia del collective bargaining o negotiation, entendiendo por esta la exploración de condiciones laborales por mejorar que ha de ser objeto de negociación con el empleador y que estos NNMMSS han realizado mediante la 
citada afiliación, al compartir presencia en sus respectivas organizaciones y en determinados sindicatos, con mayor o menor representatividad (Brunet i Icart y Moral Martín, 2020).

Todas estas estrategias quedan completadas por otras que no son utilizadas por estos NNMMSS, pero que pasamos a describir: restructuring, que se refiere a las posibilidades de fusiones entre sindicatos individuales, o bien de estrechar lazos entre confederaciones o internacionalizar las vinculaciones de estas organizaciones: coalition-building, con lo que se hace mención a las alianzas entre sindicatos y otros movimientos sociales, dando el clásico ejemplo de las alianzas por el medio ambiente y, por último, international solidarity, que se entiende como la necesidad de promover la creación de actuaciones y acciones sindicales a nivel internacional que traten de contrarrestar las posibilidades abiertas por la globalización como, por ejemplo, la movilidad del capital, claramente reflejada en las cadenas de producción internacionales y en los servicios financieros ${ }^{1}$.

Por todo lo expuesto, se comprende que se trata de una serie de actuaciones que pretenden ampliar los límites analíticos del complejo contexto que conforma el tándem neoglobalización/capitalismo y que tanto juego ha dado para esta cuestión. Para comprender esta relación, recuperamos el análisis de Checchi et al. (2010) acerca de las vinculaciones entre afiliación y ciclos económicos, adelantadas por Kalecki (2011) a mediados del siglo XX, cuando demostró que el pleno empleo fortalece el sindicalismo, mientras que el desempleo y la precariedad lo debilita. Hablamos de una correlación que aparece en la base del discurso sindical, a veces claramente exculpatorio, y que asume exclusivamente la teoría de la demanda. Desde estas organizaciones de trabajadores se señalan como únicos culpables de su situación los aspectos externos (estructuras de empleo y gestión empresarial y modelos de gestión de la mano de obra, globalización y neoliberalismo, entre otros), cuya repercusión, para Beneyto Calatayud (2018), en el citado declive señala la ignominia del neoliberalismo que acusa exclusivamente a los factores de oferta (internos al sindicalismo) de la actual situación.

Si bien estos factores aportan buenas razones para explicar el citado declive, resultan parciales. En este sentido, las causas externas no parecen explicar totalmente el porqué de la desafección sindical y la consecuente pérdida afiliativa, lo que apuntaría hacia la presencia de causas más profundas. Köhler y Calleja Jiménez (2015) así parecen señalarlo al describir como un grito una de las principales contestaciones ante la que se encuentran ciertas instituciones representativas, también los sindicatos: "They don't represent us!".

Precisamente esta carencia analítica parece ubicarse en el centro de la aparición de los NNMMSS, cuyas relaciones con los sindicatos forman parte de la denominada por Hyman y Gumbrell-McCormick (2017) geometría variable ${ }^{2}$. Al menos en España, estos movimientos sostienen una serie de críticas hacia las centrales sindicales al culpabilizarlas también de su situación, vinculándolas a ciertas actuaciones internas (Barranco y Molina, 2014), entendien-

1. Seguimos las descripciones de Frege y Kelly (2006: 33-35).

2. Nuevas formas sindicales que han aparecido en numerosos países. Para centrarlo solamente en los países vecinos, con los que compartimos el modelo sindical mediterráneo, tenemos los trabajos para Portugal de Costa et al. (2014) y para Francia de Kesselman y Sauviat (2017). 
do que sin su asunción sindical resultará más compleja su revitalización ${ }^{3}$. Esto ha supuesto recuperar la teoría de la oferta, basada en el replanteamiento crítico sobre la participación de los trabajadores centrales y sindicatos más representativos y la configuración y los límites de la negociación colectiva para la mejora de las condiciones laborales de estos colectivos concretos, todo ello sin olvidar el hecho cierto de la existencia de determinadas transformaciones en el camino correcto ensayadas por las propias centrales sindicales como la fusión de federaciones y la centralización de la negación colectiva, entre otras señaladas por Calleja Jiménez (2017).

\section{Método y diseño de la investigación}

El estudio de esta situación ha demandado un enfoque metodológico cualitativo y transversal, utilizando las técnicas de entrevistas semiestructuradas y de análisis crítico de textos y documentación. El objeto es estudiar cómo las críticas aportadas por los NNMMSS han recuperado la denominada teoría de la oferta, que pone el foco en la responsabilidad interna de los sindicatos más representativos, para incorporarla junto a la de demanda y así explicar con mayor amplitud su actual situación. Este conjunto de actuaciones deberían ayudar a los sindicatos mayoritarios a renovarse, asumiendo e interiorizando sus propuestas, tal como lo han hecho tradicionalmente con los "nuevos" (aparecidos en las décadas de 1960 y 1980) y los "novísimos", de los últimos años, movimientos sociales (Beneyto Calatayud, 2017), si bien en este caso el interés recae en que estos NNMMSS han sido creados fundamentalmente por mujeres y jóvenes, colectivos tradicionalmente poco representados por los citados sindicatos 5 .

El enfoque ha sido transversal, con una sola entrevista por participante. El trabajo de campo se basó en un conjunto de entrevistas en la ciudad de Barcelona, donde residen las direcciones de las organizaciones entrevistadas, si bien su ámbito engloba a toda Cataluña. En concreto se han realizado dieciséis entrevistas semiestructuradas (Anexo 1) de una hora aproximadamente de duración a varios miembros accesibles y representativos. Todas las entrevistas se llevaron a cabo en el periodo comprendido entre octubre y diciembre de 2017.

El guion temático utilizado en este trabajo se ha centrado en dos aspectos principales: 1) valoraciones presentes y futuras del sindicalismo en general, en el que surgió la cuestión del

3. El debate de fondo sobre el que se circunscribe tiene que ver con la confrontación de dos orientaciones sindicales históricas. Así, frente a las ideas de las relaciones económicas, defendidas por el matrimonio Webb, y vinculadas a las grandes centrales sindicales, parece recuperarse el proyecto moral y ético de justicia sindical, encabezado por Durkheim (Costa y Estanque, 2019).

4. También incluir el proyecto digital de la UGT que ofrece soporte laboral a los trabajadores de plataformas digitales. Más información, en: http://www.turespuestasindical.es/.

5. Esta es la razón por la que la creación de estos NNMMSS no la contemplamos bajo la óptica del denominado Social Movement Unionism (SMU), descrito por Köhler y Calleja Jiménez (2015) como el conjunto de alianzas establecidas entre entidades sociales y sindicatos, ya que en nuestro caso son organizaciones parasindicales que mantienen relaciones de igual a igual con los sindicatos tradicionales (con mayor o menor representatividad), pero dentro de la lógica de la separación organizativa y de actuación estratégica. Un amplio estudio de estas alianzas del SMU, en Heery et al. (2012) y Martínez Lucio y Perrett (2009). 
asamblearismo como alternativa organizativa interna; y 2) la representación unitaria, que ha sido contestada mediante la estrategia de afiliación múltiple por parte de los NNMMSS. Todos los entrevistados fueron intencionalmente seleccionados por su capacidad de ofrecer información relevante, adecuada, detallada y profunda sobre el sindicalismo. Con esta selección hemos pretendido obtener cierta homogeneidad muestral (Pole y Lampard, 2002), para poder relacionar sus contestaciones con el objetivo de esta investigación y establecer relaciones teóricas. El muestreo intencional, no probabilístico y de colección completa se ha basado en los siguientes criterios de selección: a) dos académicos expertos en el estudio del sindicalismo (UNV); b) otros tantos exdirigentes sindicales de $\mathrm{CONC}^{6}$ (E-SDT); c) tres dirigentes de UGT y dos de CONC (SDT); d) un dirigente de Fomento del Trabajo (PTL); y e) varios dirigentes de NNMMS (NMS). En concreto dos de Las Kellys Unión Cataluña (LKUC), otros tantos de La Marea Azul (LMA), técnicos de contratas y subcontratas de Movistar y un representante de RidersxDerechos (RxD), repartidores de comida a domicilio.

Paralelamente, se ha llevado a cabo un análisis crítico de su discurso (Alonso Benito, 2003). En este sentido, cada una de las entrevistas ha sido analizada en su contexto social y particular concreto, relacionándolo con la numerosa literatura que existe alrededor del mundo sindical sobre su declive y su revitalización. Además, se ha recurrido a datos secundarios para contextualizar la realidad de Cataluña a nivel de estructura sindical, cuyo sector privado está claramente dualizado por Comisiones Nacionales Obreras de Cataluña (CONC), con un 42,3\% de los representantes elegidos, y por Unión General de Trabajadores de Cataluña (UGT), con un 39,49\%, según los datos ofrecidos por IDESCAT ${ }^{7}$ sobre las elecciones sindicales a 31 de diciembre de $2018^{8}$. Esta mayoría de delegados les otorga una mayor representatividad en los sectores en los que operan los NNMMSS: hostelería y turismo (LKUC), metal (LMA) y comercio (RxD).

Esta hegemonía en el citado sector privado parece gozar de buena salud, toda vez que estas centrales sindicales mayoritarias comienzan a recuperarse de la pérdida afiliativa sufrida desde el comienzo de la crisis. El estudio de Jódar et al. (2017: 70) sobre CONC así lo señala: "con cierto desfase temporal experimentó una fuerte dinámica positiva en el crecimiento y una profunda caída en la crisis [2007] y, en 2016, se observa una relativa estabilización"9. No obstante, existen ciertos comportamientos que se deben analizar por sus repercusiones sobre la afiliación: "permanencias más breves entre los nuevos afiliados del período 2008-2014; al tiempo que la afiliación tradicional, más estable, ha experimentado un retroceso notorio". En este sentido, un dirigente de UGT señala una posible causa parcial para este tipo de comportamiento que cuestiona la cuestión de la fidelidad sindical: "las causas mayoritarias de las bajas

\section{Comisiones Obreras Nacionales de Cataluña.}

7. Información disponible en: http://observatoritreball.gencat.cat/ca/ambits_tematics/relacions_laborals_qualitat_treball/relacions_laborals/eleccions_sindicals. Visitado el 20 de julio de 2020.

8. Los restantes sindicatos obtuvieron lo siguiente: USO, un 4,73\%, y CGT, un 2,63\%.

9. Recientemente Comisiones Obreras de Cataluña ha cuantificado el incremento de su afiliación para el año 2018 en un 1,19\%, lo que sitúa su militancia en 142.689 sindicalistas. Disponible en: www.ccoo.cat/aspnet/noticia. 
han sido prácticamente económicas. [...] cuando la gente no tiene trabajo, pues de lo primero que se va quitando es de temas que considera que en ese momento no los va a necesitar" (SDT02).

En relación con los datos de afiliación aportados por los NNMMSS, son prácticamente inexistentes, por lo que no podemos valorar su posible incidencia en la competencia afiliativa entre estos y los sindicatos desde el punto de vista cuantitativo. Tampoco del resultado de las entrevistas se ha podido obtener una correcta visión cuantitativa. Mientras que los representantes de LMA y RxD no dijeron nada sobre su número de afiliados, LKUC, por boca de su presidenta, cuantificó vagamente este número al vincular afiliación con presencia en redes sociales propias: "en el grupo de Facebook, ya vamos por 11.300 " (NMS01) ${ }^{10}$. No obstante, la previsible escasa afiliación plantea más un problema de calidad, sobre el grado de cumplimiento de su exigida transparencia, que uno de números. Sin embargo, hemos de tener presente que en su origen la formación del sindicalismo español estuvo vinculada a "balbuceos de minorías", en celebrada expresión de Bahamonde (2017: 192), con la energía suficiente como para independizarse de los partidos políticos que vehiculizaban supuestamente sus propuestas. En este sentido de pujanza es en el que estas nuevas experimentaciones salariales se asemejan a sus, ya lejanos, precedentes.

\section{Asamblearismo como propuesta alternativa participativa a la representación por delegación}

Entre las quejas más frecuentes emitidas por los NNMMSS se encuentran las formas de participación en las centrales sindicales mayoritarias. Muy resumidamente, estas se oponen a una fórmula basada en la delegación al entender que les limita su participación en la elección y control de las estrategias de la acción sindical (Barranco y Molina, 2014), por lo que proponen una experiencia más horizontal basada en el asamblearismo, con el objetivo de resultar más atractivas a la posible afiliación en términos estratégicos vinculados al organizing, que ha sido ubicado por Martínez Lucio (2008: 121) "en el centro de la renovación sindical”. Esta forma de representación es utilizada en función de los intereses de sus afiliados y en las conveniencias organizativas, por lo que observamos cómo esta es llevada de diferentes maneras.

Tenemos el caso del encuentro físico de LMA, lo que parece vincularlo al denominado sindicalismo de organización propuesto por Milkman y Voss (2004) y "basado en establecer formas de reclutamiento fuera de los centros de trabajo y vinculados a espacios amplios de trabajo, como polígonos, aeropuertos y centros comerciales. Con ello se trata de afiliar a colectivos

10. Las Kellys afirman que son el 30\% de las plantillas hosteleras. Información disponible en: https://mats-sanidad.com/2017/11/06/cesion-ilegal-trafico-trabajadoras/. 
reacios a ello (precarios, e inmigrantes, entre otros) y desplazarlos hasta el mismo centro de las acciones reivindicativas, empoderándolos". También podemos observar la participación virtual, como lo señala el caso de LKUC, y que parece acercarse al denominado, por Waterman y Wills (2001), sindicalismo de Internet "cuya aportación consiste en su utilidad para preparar determinados tipos de acción colectiva, como campañas concretas y boicots, permaneciendo fuera del control empresarial" (Brunet i Icart y Moral Martín, 2020: 170-171).

A la hora de analizar las limitaciones de la participación en las estructuras sindicales, esta se ha de vincular a la táctica defensiva que las centrales sindicales han desarrollado para enfrentarse a una situación compleja y que pasamos a desarrollar. Según Antentas (2008: 30), esta situación se puede describir incorporando tanto factores provenientes de la teoría de la demanda como de la oferta: "la pérdida de afiliación en muchos países (aunque no en todos); la caída de la participación interna de los afiliados en la vida sindical, que expresa un debilitamiento de la base social real de los sindicatos; la reducción de la conflictividad laboral; una crisis de función debido a los procesos de individualización de las relaciones laborales que cortocircuitan a los sindicatos; y la disminución de su influencia social".

Otra explicación mucho más política es la propuesta por Kloosterboer (2008: 120-121), para quien "muchos sindicatos europeos gozan de una fuerte presencia institucional por lo que el incentivo para integrar nuevos tipos de trabajadores es relativamente débil". Esta situación parece generar una evidente contradicción para el caso español, por el hecho de que "dicha pérdida de influencia social y declive de fuerza real se haga en paralelo a una mayor institucionalización" (Antenas Collderram, 2008: 30). En la misma línea, Lahera Forteza (2016: 6) señala sus consecuencias al nivel de la militancia: "en España existe un generalizado desincentivo a la afiliación a los sindicatos, sin salida con las reglas vigentes de juego", lo que quizás ayudaría a entender la actual situación de tensión real entre organizaciones, así como también el alejamiento de ciertos sectores y colectivos. El propio Lahera Forteza (2018: 20) reconoce la aportación del sindicalismo, señalando que "ha dotado a nuestro país de estabilidad y paz social frente a todas las coyunturas". Sin embargo, en su opinión estos logros no deben ocultar algunos de sus aspectos más controvertidos como el de su excesiva institucionalización sindical, que contribuye a desincentivar la afiliación.

Existe otra explicación basada en la acción sindical, la aportada por Martínez Lucio (2008), quien ha señalado que hacia finales del siglo XX se produjo un incremento de la desregulación económica presionado por el neoliberalismo. Frente a ello las centrales sindicales apostaron estratégicamente por ampliar la negociación colectiva, si bien asumiendo la pérdida de capacidad de confrontación. En España esto supuso alejarse de determinados colectivos con menor poder de negociación, ofreciéndoles la posibilidad de participar por delegación. Este aspecto ha sido estudiado por Checchi et al. (2010: 85), quienes explicaron que los colectivos de menor retribución se ven obligados a confiar "en el mayor poder de mercado de aquellos con mayores habilidades para lograr mejoras para aquellos con menor poder de mercado".

De todo lo expuesto se deduce la limitación a la participación de colectivos muy concretos en un tipo de sindicato que según Khöler (2008) ha iniciado una reconversión hacia "guardianes de la empleabilidad de las personas, en agentes de intermediación y de formación conti- 
nua, y en organizadores de la rotación de empleados", lo que reduce su capacidad de lucha y confrontación. Esta estrategia se ha rechazado y alabado a la vez. Por parte de los dirigentes de LMA se los acusa de que "solventan huelgas con los menores daños posibles hacia la patronal" (NMS04), táctica que es criticada por lo que ha supuesto de abandono de las bases sindicales: "hace años que dejaron de hacer sindicalismo de base", y por su supuesta corporativización: "no vamos a decir [que están] a la voz de la patronal, pero sí se acercan mucho" (NMS04). Por el contrario, el representante de la organización empresarial lo presenta como garantía de estabilidad: "intentar evitar conflictividades laborales y generar la máxima paz social posible" (PTL01).

A nivel organizativo ha existido una evidente repercusión en la representación. Drolas (2009) ha señalado que las centrales sindicales mayoritarias han sido cooptadas por sus dirigentes, lo que ha dejado fuera del ámbito de decisión a sus afiliados. Esta situación ha fomentado la búsqueda de sistemas participativos más dinámicos, lo que pudiera encontrarse en la base de la buena imagen que entre los NNMMSS tiene el asamblearismo, como un sistema representativo individual al que revisten de todas las garantías democráticas, frente a unas decisiones por delegación controladas y al parecer incapaces de generar una participación adecuada de sus miembros. Así pues, el organizing se ha convertido en una de sus principales estrategias para atraer e incrementar su afiliación.

Vinculado a este sistema de representación, los NNMMSS nos ofrecen un tercer elemento explicativo, el de su inadecuación a los cambios estructurales del mercado de trabajo. El representante de RxD señala el abandono y la falta de interés que perciben como organización: "el sindicalismo actual ha olvidado a una parte de trabajadores que están surgiendo a través de la nueva manera de hacer economía, el nuevo modelo productivo, el mundo de las Apps, de las Start-Apss, de los falsos autónomos..." ${ }^{11}$. Se trata de una interpretación cercana a la idea del "unwilful ignorance" del sindicalismo manifestada por sus colegas belgas de Deliveroo (Vandaele et al., 2019). En su opinión, se preocupan por una serie de sectores históricamente más estabilizados, frente a otros: "la precariedad laboral que hay hoy en día. Y se han centrado solo en sus sectores de toda la vida, en el metal, el 'noséqué'... Y ahí están muy bien, tienen su parafernalia montada. Entonces, en ese sentido se han quedado un poco atrás" (NMS05).

Este aspecto ha sido destacado por un académico, al señalar que la aparición de nuevos sectores productivos dificulta establecer la identidad colectiva de la que históricamente se ha nutrido el sindicato de mediados del siglo XX: "las tres M: male, manufacturer y manual" (UNV01). Otro académico, especializado en la historia de CC.00., señala que toda la izquierda, incluyendo a los sindicatos, incorporó críticamente "eso que se llamó fordismo y taylorismo" (UNV02). De ahí que históricos militantes sindicales clamen por "zafarse definitivamente de su contagio [taylorista]” (López Bulla y Tébar Hurtado, 2017: 32). Ante semejantes situaciones, se sucedieron respuestas similares de sindicalización. Un antiguo dirigente de CONC rememora la creación del sindicato de mujeres taquilleras del metro de Barcelona: "cosa que yo les desaconsejé [...]. Pero lo entendí perfectamente, si a las criaturas nadie las defiende, ¿qué hacen ellas?" (E-DST01). 
En una línea similar se encuentra el colectivo de las camareras de piso de Cataluña (LKUC), perteneciente a las "Kellys Confederadas [...], una confederación de asociaciones". Su caso resulta especialmente paradigmático, tal como ha sido descrito por otro antiguo dirigente de CONC, ya que su aparición "pone en evidencia la grave contradicción [entre beneficios y salarios] en un sector económico importante" (E-DST02). Aquella organización parte de la teoría de la oferta para describir el momento sindical: "creo que los sindicatos [más representativos] están un poco a la baja [...] tienen un pasado y, evidentemente, no han hecho las cosas como deberían". En su opinión, y vinculado a la participación, esto ha provocado la aparición de nuevas experiencias a la búsqueda de una mejor integración: "han surgido muchísimos sindicatos nuevos", lo que supone su fragmentación: "la gente se está empezando a cansar y se organiza como colectivo". Este hecho ha supuesto una lacerada crítica a su hegemonía, no así hacia su existencia: "los sindicatos van a quedar, ya lo he comentado alguna vez con las compañeras, como las compañías de teléfonos" (NMS01).

Esta falta de participación, real o no pero así percibida, ha supuesto culpabilizar a las centrales sindicales mayoritarias de sus deficientes condiciones laborales por su negativa a comprender su situación concreta y su falta de atención. En el caso de LKUC, esta relación es muy evidente: "el problema que nosotros teníamos no nos lo ha sabido solucionar nadie [tampoco los sindicatos]" (NMS02). Afirmación ratificada por Ángela Muñoz, vicepresenta estatal de Las Kellys $^{12}$, quien tras su entrevista con el entonces presidente del Gobierno declaró: "estamos hartas de que gente que no sabe hacer una cama, ni lo que supone hacer veinte habitaciones y que te paguen dos euros, se pongan a defender derechos que a ellos no les van a afectar".

Por todo lo expuesto no resulta extraño comprender por qué estos NNMMSS han utilizado la estrategia del organizing de la siguiente manera: primero, organizándose y, segundo, atrayendo afiliación al basarse en sistemas horizontales de participación y representación e impulsando un sistema asambleario que tenga en cuenta las especificidades propias según el colectivo al que nos remitamos. Así, LMA goza de una alta concentración de trabajadores en entornos geográficos cercanos; por este motivo no dudan en celebrar sus encuentros de forma física, en los que casi todo se somete al escrutinio de los militantes. Uno de sus dirigentes afirma que, salvo aspectos basados "en el incumplimiento de una ley [...], todo lo demás lo hacemos asambleario. Entonces, lo que diga la asamblea. A unos les parecerá mejor [que] a otros..., pero la asamblea manda siempre" (NMS04).

Situación diferente es la que presenta $\operatorname{LKUC}^{13}$, ya que la dispersión geográfica que sufren, la escasa concentración por centros de trabajo y su constante de género les aconseja la utilización de medios de encuentros no físicos, por lo que se vinculan al uso de las nuevas tecnologías: "para nosotras las redes sociales han sido una salvación [organizativa]. Han puesto a nuestros medios herramientas que a nosotros de otra manera... A ver, yo antes por ejemplo si mi hijo

12. Información disponible en: https://www.eldiario.es/clm/Kellys_0_767823948.html. Visitado el 04 de noviembre de 2018.

13. Una clara estrategia en este sentido es el denominado sindicalismo del bizcocho. LKUC organiza una merienda en la que preparan este tipo de dulces, con el que dan comienzo a una campaña de afiliación. Para Brunet i Icarty Moral Martín (2020: 236): "esta consiste en captar militantes, pero en un ambiente alejado del centro de trabajo $y$ de los recursos organizativos sindicales, con la inestimable ayuda de las redes sociales". 
era pequeño y yo tenía trabajo en casa... yo no tenía tiempo material para dedicarme a ninguna acción sindical. No tenía tiempo material. ¿Qué pasa? Que ahora con las nuevas tecnologías, ese tiempo material me lo saco de la cama, por decir, en la cama dormida por la noche... que son las diez de la noche y tú te metes con el móvil y te metes en el grupo de WhatsApp". Estas nuevas tecnologías les han posibilitado organizarse respetando los principios asamblearios: "votando por WhatsApp: 'A ver, ¿quién quiere que salga presidenta, quién quiere que salga secretaria?'. La democracia llevada al pueblo, ¿no?, llevada al nivel de la asociación" (NMS01).

Un último ejemplo del uso de estos sistemas de participación lo ofrecen los RxD, quienes mantienen una relación contractual por cuenta ajena: "somos autónomos porque la empresa nos contrata, pero ellos no tienen ningún tipo de control o de responsabilidad con sus trabajadores, entre comillas", por lo que tienen claro que "la definición es de falso autónomo". Nos encontramos ante un asunto que depende de un debate actual en sede judicial y aún por resolver ${ }^{14}$. Como consecuencia de esta situación, han decidido integrar los citados procesos participativos en el sistema económico, por lo que han optado por la creación de una empresa social que plantee "una alternativa a este modelo económico [Deliveroo]. Y entonces, estamos iniciando el proceso de creación de una cooperativa de mensajería, que se trabajaría como ya lo habíamos hecho antes, pero con condiciones que nosotros creemos que son bastante dignas" (NMS05).

\section{La afiliación múltiple como táctica externa de intervención sindical}

El sistema español de representación sindical ha sido descrito por Redero San Román (2008) como plural y bipolarizado. Stanzani (2004), años antes, utilizó un término que ha causado más fortuna, el de dual. Recientemente, Jódar et al. (2018) lo han descrito como de doble canal confirmando la preponderancia de su pluralidad y estructurándolo bajo la terna empresa, sector e institucionalidad. Como resultado de todo ello, Lahera Forteza (2018) resalta la existencia de dos órganos diferentes, pero paralelos, de participación y negociación de los trabajadores en sus empresas: el electivo (estatutario) y el afiliativo (sindical). Tal situación favorece la utilización de complejas estrategias de representación y de negotiation, tal como nos lo muestran los NNMMSS. Este hecho parece señalar que el actual sistema de representación padece de una clara falta de adaptación.

Desde sus orígenes en 1977, el sistema sindical de doble canal español nació con evidentes rasgos neocorporativistas, tal como ha sido descrito por Jódar et al. (2018: 16-17): "la re-

14. Ver artículo: "Un juez falla por primera vez que un repartidor de Glovo sí es un falso autónomo". Disponible en: https://elpais.com/economia/2019/02/13/actualidad/1550081374_920144.html. Si bien parece que con la "Ley Riders", el Ministerio de Trabajo busca regular los riders como asalariados antes del fin del verano. Información disponible en: https://cincodias.elpais.com/cincodias/2020/06/03/economia/1591208971_993495.html. Visitado el 20 de julio de 2020. 
presentatividad obtenida mediante elecciones potencia la legitimación de los sindicatos más votados, pero también su presencia en la negociación colectiva con la pretensión de favorecer acuerdos y pactos sociales". Esta descripción señala claramente que su intencionalidad residió en la búsqueda de grandes acuerdos institucionales para asegurar la pax social del sistema. Se consiguió el éxito en sus comienzos, si bien seguido por dificultades según las distintas etapas. En opinión de Pérez-Díaz (1986) este hecho sucedió casi de forma fortuita, al ser la mejor fórmula encontrada entre el Gobierno y los diferentes agentes sociales en aspectos como la defensa de sus propios intereses y la recíproca búsqueda de legitimidad.

Nos hallamos frente a una simultaneidad de dos canales de representación, el electivo y el sindical, que como acabamos de ver fue la consecuencia del encuentro entre dos modelos laborales: el predemocrático y el plenamente democrático. Baylos Grau (1991) describió su configuración durante el periodo de vacío transitorio entre la transición y la recuperación de la democracia, mostrándolo como el resultado de un conjunto de concesiones que las dos centrales más representativas se hicieron en plena democracia: CC.00. era favorable a la representación electiva, en forma de comités de empresa, mientras que UGT defendió la sindicalización en la empresa, a través de secciones y delegados sindicales. Redero San Román (2008: 129) ha señalado cierta limitación en este comportamiento, al menos en sus inicios: "los sindicatos, en especial la UGT, exploraron desde 1979 la vía de la concertación social y de los pactos neocorporativos, pero en 1986 dicha vía quedó abandonada". Las negociaciones lograron dotar al sistema de "estabilidad y paz social ante todas las diferentes coyunturas" (Lahera Forteza, 2018). En este sentido, este neocorporativismo parecía recuperar su función histórica de doctrina social, descrita por Fernández Riquelme (2012: 165) como "la mediación entre trabajo (obreros) y capital (patronos), protagonistas de la [histórica] Cuestión social".

Para conocer ambos sistemas representativos, y poder valorar la tensión a la que están siendo sometidos, pasamos a contextualizarlos en sus respectivos ámbitos. Legalmente, la representación sindical a nivel de los centros de trabajo privados se encuentra recogida en el Título II del Real Decreto Legislativo 2/2015. Este reconoce a la Representación Sindical Unitaria (RSU) como el resultado de la representación electiva o unitaria (delegados de personal y comité de empresa) mediante elecciones sindicales. La fórmula sindical se rige por la Ley Orgánica de Libertad Sindical (LOLS) de 11/1985, que "reconoce la acción del sindicato en la empresa a través de las secciones sindicales" (Lahera Forteza, 2018: 19), siendo obligatoria la existencia de afiliados en el centro de trabajo o empresa.

El resultado de todo ello ha sido descrito actualmente por Lahera (2016:21) para justificar nuestro modelo sindical de baja afiliación: "el reconocimiento de los representantes sindicales en la empresa, desarrollado en la LOLS de 1985, a cambio de la potenciación y protagonismo de las funciones sindicales de los representantes electivos o unitarios, convertidos, además, en el eje del sistema, al adoptar el legislador un modelo de representatividad sindical sobre la base de los resultados electorales y no de la afiliación".

La cuestión de la representación y de la participación se ha de ubicar dentro de la estrategia del collective bargainig, a la que le añadimos al final de este apartado la political action, ya que su actuación necesita de la creación de una organización previa y por lo tanto pertenece 
a la estrategia del organizing, aunque no deja de situarse en el contexto de las negociaciones, legislativas en este caso, y por este motivo lo recogemos aquí. En todo caso, todas estas actuaciones han sido objeto de desarrollo por los NNMMSS, aunque las posiciones tampoco están tan alineadas como pareciera, lo que demuestra la falta de una identidad colectiva entre estas formas alternativas de representación sindical (Brunet i Icart y Moral Martín, 2020). Sin embargo, y analizando sus comportamientos en lo referente a la negotiation, se observa cómo el sistema de representación dual puede retorcerse hasta no poder reconocerse sus límites. En concreto, nos referimos a la existencia de la ocupación de los sistemas de representación por parte de una extraña alianza entre sindicatos y estas nuevas fórmulas sindicales. Por ello, nos centramos mayoritariamente en el ámbito de la empresa y (en menor medida) en el sectorial. Comenzamos por este último.

Para interpretar las dificultades que acompañan a la participación sectorial, adquiere una gran importancia la opinión desde las centrales sindicales sobre el por qué no se los reconoce como iguales. Un dirigente de CONC señala la cuestión de la institucionalidad frente a la corporatividad como uno de los principales obstáculos que las separan: "[ante] una defensa corporativa de los intereses de ciertos colectivos [vinculados a los NNMMSS], nosotros vamos a una defensa más generalista de los intereses del conjunto de los trabajadores" (SDT05). Por su parte, la otra gran central sindical en Cataluña, UGT, destaca sus intentos de aproximación: "nosotros lo que hacemos es intentar acercarnos a ellos y seguir luchando por ellos" (SDT04), si bien asumen cierta autocrítica impregnada de proteccionismo: "nos cuesta mucho organizar a los trabajadores precarios" (SDT01); "somos poco flexibles y ágiles" (SDT03).

Estas actuaciones son contestadas desde los NNMMSS por su instrumentalización. Ángela Muñoz, vicepresidenta estatal de Las Kellys ${ }^{15}$, en mayo de 2018, declaró: "ya le dijimos al presidente que no necesitamos más estudios o mesas en las que no estamos las camareras de piso", por lo que una de sus dirigentes se siente en la obligación de reclamar su presencia activa: "pediría a los sindicatos y a los empresarios que, a partir de ahora, nos tengan en cuenta para estar en la mesa negociadora" (NMS02). No se trata de una demanda menor, ya que, como ha explicado Cruz Villalón (2016: 15), participar en la negociación colectiva "otorga una enorme responsabilidad y una nada agradable función de materialización de la distribución de tales sacrificios".

Siguiendo con la negociación, pero en el ámbito de la empresa, nos encontramos con una estrategia común para lograr participar, como es la afiliación múltiple, táctica que les permite compatibilizar su actividad en la asociación con su participación en otras organizaciones salariales. LKUC no opta a las elecciones sindicales, ya que no se ha planteado constituirse, al menos a corto plazo, en sindicato, por lo que tampoco puede crear secciones sindicales: "crear una infraestructura sindical es muy complicado y yo creo que ya hay muchos sindicatos" (NMS01).

No obstante, LKUC ha logrado participar en la RSU mediante su duplicidad afiliativa, si bien con diferentes grados de vinculación. Una de sus dirigentes afirma: "sigo afiliada a CC. 00.".

15. Información disponible en: https://www.eldiario.es/clm/Kellys_0_767823948.html. Visitado el 4 de noviembre de 2018. 
Otra mantiene una relación diferente: "pertenezco [desde] hace seis años al comité de empresa, pero no estoy afiliada a comisiones" (NMS02). Esta pluralidad descansa sobre una evidente falta de compromiso ideológico, por lo que prima el oportunismo: "cuando una chica nos viene a comentar lo que pasa en su hotel, nosotras no la lanzamos a la boca del lobo, no le decimos: 'Oye, tú vas a hablar con el jefe y le pides...', no. Nosotras decimos: 'A ver, ¿cuándo son las elecciones sindicales en tu hotel?, bueno pues búscate un sindicato que merezca tu confianza y afíliate'" (NMS01). Ambas situaciones son características de estos NNMMSS, ya que terminan ocupando lugares en la RSU con o sin afiliación a los sindicatos que representan. En todo caso, todos ellos se encuentran organizados en otros movimientos sindicales.

Otro caso es el de LMA (Brunet i Icart y Moral Martín, 2020), que continúa demostrando el nivel de distorsión que supone para las empresas las elecciones a la RSU. Este colectivo de técnicos instaladores tampoco se ha configurado como sindicato, si bien se autodefinen como "una Coordinadora de trabajadores y delegados sindicales de distinta y diversa afiliación, incluyendo a personas de CC.00. y UGT", que pretende "coordinar a todas las fuerzas sindicales del sector"16. No obstante, su conversión sindical es un tema aún pendiente. Según uno de sus dirigentes es algo que no se ha descartado, pero que aún no supone un elemento central de sus debates: "sabemos que va a ser muy difícil consolidar la Marea Azul como un sindicato. [A] Todo eso hay que añadirle motor" (NMS03), por lo que tampoco pueden crear secciones sindicales.

Esto explica por qué optaron por la figura de la multiplicidad afiliativa. En su caso esta vino como consecuencia de su descontento con las centrales sindicales. En un primer momento, se decantaron por afiliarse a uno de los sindicatos mayoritarios: "fuimos primero a CC. 00. para montar un comité de empresa. No nos atendieron, tardaron mucho, así que nos fuimos a la UGT. UGT vino rápido y se montaron unas elecciones. Las ganamos y en ese momento nos afiliamos" (NMS04). Transcurrido un tiempo, creyeron comprender que UGT se encontraba demasiado limitada en su acción sindical, ya que en su opinión "no se estaba haciendo un sindicato de clase" (NMS03), por lo que decidieron afiliarse al sindicato de Comisiones de Base (co.bas) ${ }^{17}$. Este hecho dio lugar a una afiliación doble (en su caso triple: a UGT como miembros del comité de empresa, a co.bas y a LMA).

Su pertenencia a co.bas obedecía a una clara estrategia representativa, ya que desde este sindicato trataron de convocar elecciones sindicales: "es tan abrumadora la mayoría y es tan palpable que los trabajadores están con nosotros y que se... [ganaría]" (NMS04). Pese a su convencimiento, describen el añadido del factor administrativo y de la presión de los otros sindicatos como fundamentales para impedir su convocatoria en las condiciones que estaban planteadas: "cuando se montó la convocatoria [de elecciones propuesta por co.bas] apareció CC.00. y UGT. y dijeron que hubo un inspector [de trabajo] que, por un lado, intervino la em-

16. Texto disponible en: https://teleafonica.blogspot.com.es. Visitado el 12 de abril de 2018.

17. En su página web puede leerse un resumen del porqué de su fundación: "El Sindicato de comisiones de base (co. bas) surge del enfrentamiento que parte de la afiliación de CCOO (mayoritariamente del sector crítico) veníamos manteniendo en la práctica contra los métodos y formas de hacer sindicalismo de la dirección 'oficialista' del sindicato". Disponible en: https://www.cobas.es. 
presa y en ese momento dijeron que co.bas no era un sindicato mayoritario que pudiera convocar [elecciones]. Entonces el inspector dijo: 'Bueno, co.bas no puede ser, pero les dejo a UGT y a CC.00., ustedes pueden convocar' [...] UGT dijo que no, que ellos no iban a convocar nada y CC.00. dijo: 'Nosotros lo que diga UGT'”' (NMS04).

En su opinión, la estrategia sindical de las centrales mayoritarias resultaba evidente: "de esta forma no perdían los delegados [la UGT]", ya que en su opinión: "el que genera el dinero son los delegados" (NMS04). En la actualidad en el comité de empresa sigue siendo mayoría UGT, pero la mayoría de sus delegados no están afilados a este y sí a otro sindicato menos representativo (co.bas) y a una nueva fórmula de experimentación sindical (LMA).

El último de los casos que exponemos es algo más peculiar; se trata de los repartidores de comida a domicilio. Como ya hemos señalado, este colectivo mantiene una condición contractual confusa con su empresa contratante, al basarse en la figura del trabajador autónomo. Conscientes de que esta posición jurídica les restaba capacidad para negociar y mejorar sus condiciones laborales, trataron de ordenarse salarialmente: "primero nos organizamos nosotros [RxD] y decidimos que estaría bien dotar[nos]..., ya que no podemos hacer una sección sindical, de un sindicato, porque [como] no estamos reconocidos como trabajadores, no podemos montar una sección sindical de la IAC ${ }^{\prime 18}$. Esta postura refuerza la conclusión alcanzada por Cha et al. (2019) sobre trabajadores jóvenes y sindicatos, al señalar que no existe un enfrentamiento ideológico sino cierto desconocimiento sobre el rol de los mayoritarios, lo que explicaría parcialmente su alejamiento.

Su vinculación resultó producto de su anterior análisis, así al menos lo indica su portavoz: "[algunos] miembros se afiliaron para tener una organización con estructura jurídica", para encontrar soluciones colectivas a su problemática concreta. Sin embargo, antes de afiliarse a la IAC se barajaron otras opciones: "tuvimos contactos con algún miembro de la CGT y luego vino..., porque a través de un compañero que tenía contactos con la IAC, porque... y decidimos hacerlo con ellos" (NMS05). En todo caso, el interés por la sindicalización en este colectivo concreto, como fórmula para defender sus intereses y condiciones de trabajo, es similar al manifestado por sus colegas belgas de Deliveroo, sin olvidar que la densidad sindical de su país es más alta que la española (Vandaele et al., 2019).

Paradójicamente, este forzar el sistema permite asegurar su éxito. Lahera Forteza (2018: 20) afirma que "la representación electoral de trabajadores en la empresa y la representatividad sindical por resultados electorales es, tras treinta y cinco años, un sistema estructural, más allá de toda coyuntura".

Finalmente, y por las propias implicaciones reseñadas en este trabajo, aparece un nuevo tipo de negociación por el que optan estos NNMMSS y que tiene que ver con la estrategia de la political action, al dirigirse a las administraciones públicas para que estas, vía legislación, influyan sobre la mejora de sus condiciones de trabajo. El primer ejemplo al que acudimos,

18. Intersindical Autónoma de Cataluña. Más información en: https://iac.cat. 
respetando los aconteceres cronológicos, es la denominada "Ley Kelly"19, que básicamente pretendía derogar el artículo 42 del Estatuto de los Trabajadores y así evitar la subcontratación de camareras de piso por empresas multiservicios, cuyas condiciones contractuales eran claramente peores. También, y como logro del colectivo, aunque no exclusivamente, tenemos el reconocimiento por parte de la Seguridad Social de determinadas enfermedades profesionales para este colectivo por las particulares características de su puesto de trabajo, siendo las más conocidas la del túnel carpiano, la epicondilitis y la tendinitis, para lo que se ha propuesto ampliar a este colectivo lo ya recogido en el RD 1299/2006 20.

A estas victorias legales les añadimos el caso de los RxD, cuya conocida "Ley Riders" está siendo objeto de estudio por el propio Ministerio de Trabajo para regular las condiciones de trabajo en el entorno de las plataformas digitales ${ }^{21}$. De todo ello se deduce lo siguiente: la dificultad de ciertas negociaciones vinculadas al mundo sindical trata de ser superada por otras de carácter legal. Esta situación explicaría por qué han entendido que su principal triunfo haya de venir acompañado de una legislación que los proteja. No obstante, en el actual estado de nuestra investigación no disponemos de información sistematizada sobre la repercusión de estas propuestas en la mejora de sus respectivas condiciones laborales y profesionales, lo que nos impide poder evaluar adecuadamente su impacto. Es por ello por lo que debemos seguir considerándola como un reto abierto a abordar por estos NNMMSS, al menos hasta lograr evidencias a su favor ${ }^{22}$. 


\section{Conclusión}

La aparición de NNMMSS ha provocado la necesidad de replantear algunas afirmaciones alrededor del ámbito del sindicalismo que parecían estar resueltas desde hace tiempo. Nos referimos, principalmente, a la cuestión de su declive. No resulta coherente que cuando se han dado por desaparecidos a los sindicatos, surjan nuevas fórmulas que precisamente se basan en sus aspectos básicos: asociación en torno a unas condiciones laborales similares que justifican una representación colectiva y capacidad para poder reclamar y organizar el conflicto provocado por los diferentes intereses encontrados.

En este sentido, los diferentes colectivos que hemos analizado parecen cuestionar profundamente esta tradición de estudios pesimistas en lo referente al futuro sindical, pero no solo eso. También discuten aspectos muy presentes en las propias centrales sindicales, lo que los debería retar a iniciar un proceso de reflexión acerca de cómo orientar su acción sindical para lograr aglutinar a todos aquellos colectivos salariales que, por una u otra razón, han preferido organizarse por su cuenta y acudir a sindicatos minoritarios y a los que se han afiliado principalmente a los mayoritarios, ya que esta vinculación parece obedecer a factores instrumentales más que a voluntades ideológicas o sociales, lo que cuestiona de forma profunda el ser sindical y el porqué de la elección de uno de ellos como referencia.

Dos han sido las principales demandas que hemos analizado en este texto. Hemos comenzado con los aspectos internos, centrándonos en la participación. Este comportamiento ha sido criticado ampliamente desde los NNMMSS al considerarlo como poco conveniente para lograr orientar las actuaciones que se creen necesarias, una impugnación en toda regla de una estrategia seguida por los sindicatos ante las situaciones tan complejas que, al menos desde la década de 1990, vienen sufriendo. En este contexto la orientación ha girado hacia la negociación en lugar de hacia el conflicto, de ahí el excesivo, quizás, peso de sus direcciones. Nos encontramos ante una actuación que ha estado basada en la asunción de la teoría de la demanda que situaba fuera del control de los sindicatos sus principales amenazas, como la neoglobalización, el neoliberalismo, el peso de las instituciones europeas en la gobernanza de las políticas de respuesta y ajuste y los cambios estructurales en mercados de trabajo y empresas, entre otros factores.

Las quejas emitidas por los NNMMSS sobre su escasa, y relativamente poco importante, participación han servido para situar un nuevo elemento en el centro del debate sobre la pérdida de poder sindical: cuál es su responsabilidad ante esta situación. Desde esta óptica, la aparición de nuevas experimentaciones salariales ha venido acompañada de una reedición de la teoría de la oferta, que también culpabiliza a las propias estructuras y actuaciones sindicales de parte de sus errores. En este sentido, señalan el rol de la importancia de la participación de los trabajadores centrales, así como la excesiva institucionalización de los sindicatos más representativos y la configuración y los límites de la negociación colectiva. Ante todas estas situaciones, y como enseñanza, aparece la figura de la asamblea como un elemento de participación que ayuda a reconocer errores y desviaciones al basar su soberanía decisoria en el conjunto de sus afiliados, conectada a la estrategia revitalizadora del organizing y de la political 
action. Así, y en función de las características propias de cada organización, la fórmula ha sido diferente: presencial para LMA, telemática para LKUC y empresarial (cooperativa) para RxD.

Siguiendo con los aspectos externos, señalamos la figura de la afiliación múltiple como la táctica más adecuada para participar de una representación en el centro de trabajo que parece estar dirigida hacia sindicatos tradicionales, vinculada a la renovación por la negotiation. El mérito de su presencia equivale a la astucia de su flexibilidad para poder incorporarse a un sistema cerrado y que ha logrado dotarlo de estabilidad durante las últimas décadas. La instrumentalización del uso de sindicatos con menor representatividad en su sector desde los que organizar elecciones sindicales, o el uso de las centrales mayoritarias para participar de la RSU en los diferentes centros de trabajo, junto con la utilización de un sindicato alternativo para poder organizarse como secciones sindicales trabajadores por cuenta ajena, han sido algunos de los ejemplos que hemos mostrado para corroborar las limitaciones que actualmente presenta el sistema de representación en la empresa y su apuesta por la mejora de sus condiciones de trabajo mediante la legislación.

Todo ello ha ido acompañado de una lectura muy laxa sobre la ideologización de la decisión de afiliación, contribuyendo a crear figuras de doble y triple afiliación y dando lugar a situaciones paradójicas como la de uno de los centros de trabajo en los que tiene presencia LMA, donde existe un comité mayoritario de UGT sin que esta tenga afiliados en su sección, ya que los trabajadores pertenecen a co.bas, militancia que alternan con la de su asociación de técnicos.

Finalmente, los dos comportamientos que hemos analizado de estos NNMMSS han dado lugar a una modalidad de negociación por la legislación y que hemos incluido en la estrategia de la political action, ya que viene siendo utilizada por estos colectivos, como lo demuestra su denominación popular -"Ley Kellys y Ley Riders"- y que se ha de sumar a todos los intentos por participar en las negociaciones colectivas (a nivel sectorial, pero sobre todo empresarial), y tomarlos en cuenta como otro intento más por la defensa de la mejora de sus respectivas condiciones de trabajo. Lamentablemente aún no estamos en disposición de poder valorar el impacto real sobre la mejora de sus condiciones laborales, a pesar de la existencia de indicios que señalan hacia su mejora.

\section{Bibliografía citada}

ALONSO BENITO, L.E. (2003): La mirada cualitativa en Sociología. Una aproximación interpretativa, Editorial Fundamentos, Madrid.

ALÓS, R. (2017): "Sobre el desencuentro entre sindicalismo y movimientos sociales post 15M. A propósito de unos textos de Joan Coscubiela, Erik Olin Wright y Maite Tapia, Revista Pasos a la izquierda, 9, 1-7. Recuperado el 15 de noviembre de 2017, de http://pasosalaizquierda.com/?p=2840. 
ANTENAS COLLDERRAM, J.M. (2008): “Los sindicatos ante la globalización. ¿Hacia qué nuevas formas de solidaridad internacional?", Cuadernos de Relaciones Laborales, 26(1), 35-55.

BAHAMONDE, A. (Coord.) (2017): Historia de España. Siglo XX (1875-1939), Ediciones Cátedra, Madrid.

BARRANCO, 0. \& MOLINA, 0. (2014): "Sindicalismo y crisis económica: Amenazas, retos y oportunidades", Kultur: revista interdisciplinària sobre la cultura de la ciutat, 1(2), 171-194. DOI: 10.6035/Kult-ur.2014.1.2.9.

BAYLOS GRAU, A.P. (1991): "La intervención normativa del Estado en materia de relaciones colectivas". En: MIGUÉLEZ LOBO, F. (Dir.) \& PRIETO RODRÍGUEZ, C. (Coord.), Las relaciones laborales en España, 289-306. Siglo XXI Editores, Madrid.

BEHRENS, M., HAMANN, K \& HURD, R (2004): “Conceptualizing Labor Union Revitalization”, En: FREGE, C.M. \& KELLY, J. (Eds.), Varieties of Unionism: Strategies for Union Revitalization in a Globalizing Economy, 11-29. 0xford University Press, 0xford. D0I: 10.1093/acprof:oso/9780199270149.003.0002.

BENEYTO CALATAYUD, P.J. (2017): “Crisis y renovación del sindicalismo", Arxius de Sociologia, 36-37, 15-34. https://dialnet.unirioja.es/servlet/articulo?codigo=6431781.

- (2018): "Representación sindical en la Unión Europea y España: Estructura, cobertura y nuevos retos", Acciones e investigaciones sociales, 38, 37-62.

DOI: 10.26754/ojs_ais/ais.2018382974.

BERNACIAK, M., GUMBELL-MCCORMIC, R. \& HYMAN, R. (2015): El sindicalismo europeo: ¿de la crisis a la renovación?, Fundación 1ํㅡㄹ de mayo, Madrid.

BÉROUD, S. \& BOUFFARTIGUE, P. (2009): “Introduction”, En: BEROUD, S. \& BOUFFARTIGUE, P. (Dirs.), Quand le travail se précarise, quelles résistances collectives?, La Dispute, París.

BRUNET I ICART, I. \& MORAL MARTÍN, D. (2020): Nuevas Organizaciones Sociales: El sindicalismo ante el nuevo modelo de acumulación, Anthropos Editorial, Barcelona.

BRUNET I ICART, I., PIZZI, A. \& MORAL MARTÍN, D. (2019): Industrial relations and financial globalization: Analysis of national experiences in Europe, America and Asia, Publicacions de la Universitat de València (PUV), València \& Publicacions de la Universitat Rovira i Virgili (Publicacions URV), Tarragona.

BRYSON, A., EBBINGHAUS, B. \& VISSER, J. (2011): "Introduction: Causes, Consequences and cures of union decline", European Journal of Industrial Relations, 17(2), 97-105. D0I: $10.1177 / 0959680111400893$. 
CALLEJA JIMÉNEZ, J.P. (2017): “Estrategias para la recuperación de poder sindical en España”. Lan Harremanak: Revista de relaciones laborales, 35, 290-304.

DOI: $10.1387 /$ lan-harremanak.17498.

CHA, M., DUPUY, C., HOLGATE, J., SIMMS, M \& TAPIA, M. (2019): “Unions are only as old as they feel: lessons on young worker engagement from the UK, France, Germany and the US", ETUI Research Paper-Policy Brief. European Economic, Employment and Social Policy, 2.

DOI: $10.2139 /$ ssrn.3449937.

CHECCHI, D., VISSER, J. \& VAN DER WERFHORST, H.G. (2010): "Inequality and Union membership: The influence or relative earnings and inequality attitudes", British Journal of Industrial Relations, 48(1), 84-108. D0I: 10.1111/j.1467-8543.2009.00757.x.

COSTA, H.A. \& ESTANQUE, E. (2019): “Trade Unions and social movements at the crossroads. A Portuguese view", En: Social movements and organized labour. Passions and interests. 149-170. Routledge, London. http://hdl.handle.net/10316/86808.

COSTA, H.A., DIAS, H \& SOEIRO, J. (2014): "As greves e a austeridade em Portugal: Olhares, expressões e recomposições", Revista Crítica de Ciências Sociais, 103, 173-202.

DOI: $10.4000 /$ rccs.5584.

CRUZ VILLALÓN, J. (2016): "Nuevas funciones de la negociación colectiva y alteración de su marco normativo", Revista de Economía Laboral, 13(2), 6-33. D0I: 10.21114/rel.2016.02.02.

DÄUBLER, W. (1994): “'Salidas de la crisis? Reflexiones para un cambio de los sindicatos”, En: Valdés Dal-Ré, F. (Coord.), Sindicalismo y cambios sociales, 75-88. Consejo Económico y Social (CES), Madrid.

DOELLGAST, V. \& GREER, I. (2007): "Vertical Disintegration sand the Disorganization of German Industrial Relations", British Journal of Industrial Relations, 45(1), 55-76.

DOI: 10.1111/j.1467-8543.2007.00602.x

DROLAS, M.A. (2009): "Modelo sindical y acción política: las experiencias diferenciales de dos sindicatos del sector eléctrico", Trabajo y sociedad: Indagaciones sobre el empleo, la cultura y las prácticas políticas en sociedades segmentadas, 12.

https://dialnet.unirioja.es/servlet/articulo?codigo=2935991.

EBBINGHAUS, B. \& VISSER, J. (1999): “When Institutions Matter. Union Growth and Decline in Westenr Europe", European Sociological Review, 15(2), 135-158.

DOI: 10.1093/oxfordjournals.esr.a018257.

EZQUERRA, S., GINESTA, V. \& QUESADA, J. (2015): "Metamorfosis del trabajo. Presentación”, Monthly Review. Selecciones en castellano, 3a época, 1, 15-32.

https://www.monthlyreview.org.es/3a-epoca-2015. 
FERNÁNDEZ LIRIA, C. \& ALEGRE ZAHONERO, L. (2012): “Marx y Polanyi. La posibilidad de un diálogo", Áreas: Revista internacional de ciencias sociales, 31, 55-64.

https://revistas.um.es/areas/article/view/165001.

FERNÁNDEZ RIQUELME, S. (2012): “La Historia del Corporativismo en Europa. Aproximación a las formas jurídico-políticas de representación del trabajo", Diálogos. Revista electrónica de historia, 13(1), 151-176. D0I: 10.15517/dre.v13i1.6368.

FREGE, C. \& KELLY, J. (eds.) (2006): Varieties of Unionism. Strategies for Union Revitalization in a Global Economy, Oxford University Press, Oxford.

DOI: 10.1093/acprof:oso/9780199270149.001.0001.

GARCÍA CALAVIA, M.A. \& RIGBY, M. (2016): "Recursos de poder de los sindicatos en España. Su examen a través de la negociación colectiva", Sociología del trabajo, 87, 7-24.

https://revistas.ucm.es/index.php/STRA/article/view/60369.

GARCÍA ESCRIBANO, J.J. \& MILLÁN JIMÉNEZ, A. (2017): "Sindicatos y Estado de Bienestar", Áreas: Revista internacional de ciencias sociales, 36, 97-111.

https://revistas.um.es/areas/article/view/308091.

GUMBRELL-MCCORMICK, R. \& HYMAN, R. (2013): "El movimiento sindical de Europa Occidental: tiempos duros, decisiones difíciles", Global Labour Column, 148.

HEERY, E., WILLIAMS, S. \& ABBOTT, B. (2012): "Civil society organizations and trade unions: cooperation, conflict, indifference", Work, Employment and Society, 26(1), 145-160.

DOI: $10.1177 / 0950017011426302$.

HYMAN, R. \& GUMBRELL-MCCORMICK, R. (2017): "Resisting labour market insecurity: Old and new actors, rivals or allies?", Journal of Industrial Relations, 59(4), 538-561.

DOI: $10.1177 / 0022185617714423$.

JÓDAR, P., ALÓS, R., BENEYTO CALATAYUD, P.J. \& VIDAL, S. (2017): “La gran recesión de 2007 y sus efectos sobre la afiliación sindical. El caso de CCOO de Cataluña", Arxius de sociologia, 3637, 61-73. https://dialnet.unirioja.es/servlet/articulo? codigo $=6431784$.

- (2018): “La representación sindical en España: cobertura y límites", Cuadernos de relaciones laborales, 36(1), 15-34. DOI: 10.5209/CRLA.59555.

KALECKI, M. (2011): "Aspectos políticos del pleno empleo", Revista de Economía Crítica (REC), 12, 214-222. http://www.revistaeconomiacritica.org/node/570.

KESSELMAN, D. \& SAUVIAT, C. (2017): "Les enjeux de la revitalisation syndicale face aux transformations de l'emploi et aux nouveaux mouvements sociaux". Chronique Internationale de I'IRES, 160(4), 19-37. D0I: 10.3917/chii.160.0019. 
KÖHLER, H. (2008): “Los sindicatos en España frente a los retos de la globalización y del cambio tecnológico", Documentos de Trabajo del Laboratorio Alternativas, 142.

KÖHLER, H. \& CALLEJA JIMÉNEZ, J.P. (2015): “'They don't represent us!' Opportunities for a Social Movement. Unionism Strategy in Spain", Relations industrielles. 70(2), 240-261.

DOI: $10.7202 / 1031485 \mathrm{ar}$.

KLOOSTERBOER, D. (2008): "Trade union strategies to organise young, ethnic minorities and atypical workers", Economia \& Lavoro, 42(3), 117-128. D0I: 10.7384/70808.

LAHERA FORTEZA, J. (2016): "Crisis de la representatividad sindical: propuestas de reforma", Revista Internacional y Comparada de Relaciones Laborales y Derecho del Empleo, 4(2): 1-18. http://ejcls.adapt.it/index.php/rlde_adapt/article/view/387.

- (2018): "Representación y representatividad sindical: puntos críticos y propuesta de reforma", Papeles de economía española, 156, 18-27.

https://dialnet.unirioja.es/servlet/articulo?codigo $=6518994$.

LÓPEZ BULLA, J.L. \& TÉBAR HURTADO, J. (2017): No tengáis miedo de lo nuevo, Plataforma Editorial, Barcelona.

MARTÍNEZ LUCIO, M. (1988): "Spain: Regulating Employement and Social Fragmentation", En: FERNER, A. \& HYMAN, R. (Eds.): Changing Industrial Relations in Europe. Basil Blackwell, London.

- (2008): “'Todavía organizaciones del descontento?: los retos de las estrategias de renovación sindical en España", Arxius de sociologia, 18, 119-133.

https://dialnet.unirioja.es/servlet/articulo?codigo=2698196.

MARTÍNEZ LUCIO, M. \& PERRETT, R. (2009): "Meanings and dilemmas in community unionism: trade union community initiatives and black and minority ethnic groups in the UK", Work, Employment and Society, 23(4), 693-710. D0I: 10.1177/0950017009344916.

MILKMAN, R. \& VOSS, K. (2004): Rebuilding Labor. Organizing and Organizers in the new Union Movement, Cornell University Press, Ithaca.

MORAL MARTÍN, J.D. \& BRUNET I ICART, I. (2018): "La imagen del sindicato en el siglo XXI a la luz de su contestación por los Nuevos Movimientos Sindicales", Sociología del Trabajo, 93, 307-326. DOI: 10.5209/STRA.61833.

PÉREZ-DÍAZ, V. (1986): "Economic Policies and Social Pacts in Spain during the Transition: The Two Faces of Neo-corporatism", European Sociological Review, 2(1), 1-19.

D0I: 10.1093/oxfordjournals.esr.a036402. 
POLE, C.J. \& LAMPARD, R. (2002): Practical social investigation. Qualitative and Quantitative methods in social research, Pearson Education, Essex.

REDERO SAN ROMÁN, M. (2008): "Los sindicatos en la democracia: de la movilización a la gestión", Historia y política: Ideas, procesos y movimientos sociales, 20, 129-158.

https://dialnet.unirioja.es/servlet/articulo?codigo=2748238.

SALAS, M. (13 de enero, 2018): "Reino de España: El salario mínimo y la estrategia sindical", Revista Sinpermiso. Recuperado el 13 de enero de 2018, de http://www.sinpermiso.info/textos/reino-de-espana-el-salario-minimo-y-la-estrategia-sindical.

SEN, R. \& LEE, C. (2015): "Trabajadores y movimientos sociales del mundo en desarrollo. ¿Cuál es el futuro de las relaciones laborales?", Revista Internacional del Trabajo, 134(1), 43-52.

DOI: 10.1111/j.1564-9148.2015.00233.x.

SILVER, B.J. (2005): Fuerzas de trabajo: los movimientos obreros y la globalización desde 1870, Ediciones Akal, Madrid.

STANZANI, C. (2004): Les systemes de représentation des travailleurs dans les entreprises en Europe, ASE-ETUI, Bruxelles.

TURNER, L. (2004): "Why revitalize? Labour's urgent misión in a contested global economy", In: Frege, C. \& Kelly, J. (Eds.), Varieties of unionism. Strategies for union revitalization in a global economy, 1-10. Oxford University Press, 0xford.

DOI: 10.1093/acprof:oso/9780199270149.003.0001.

VANDAELE, K. (2018): "Will trade unions survive in the platform economy? Emerging patterns of platform workers'collective voice and representation in Europe", ETUI, Working Paper, 2018.05. https://papers.ssrn.com/sol3/papers.cfm?abstract_id=3198546.

- (2019): Bleak prospects: mapping trade union membership in Europe since 2000, ETUI, Brussels.

VANDAELE, K, AGNIESZKA, A. \& JAN, J. (2019): "Unwilful ignorance: attitudes to trade unions among Deliveroo riders in Belgium", ETUI Policy Brief, 6/2019. DOI: 10.2139/ssrn.3448997.

WATERMAN, P. \& WILLS, J. (eds.) (2001): Place, Space and the new Labour Internationalism, Blackwell, Oxford. DOI: 10.1002/9781444397529. 


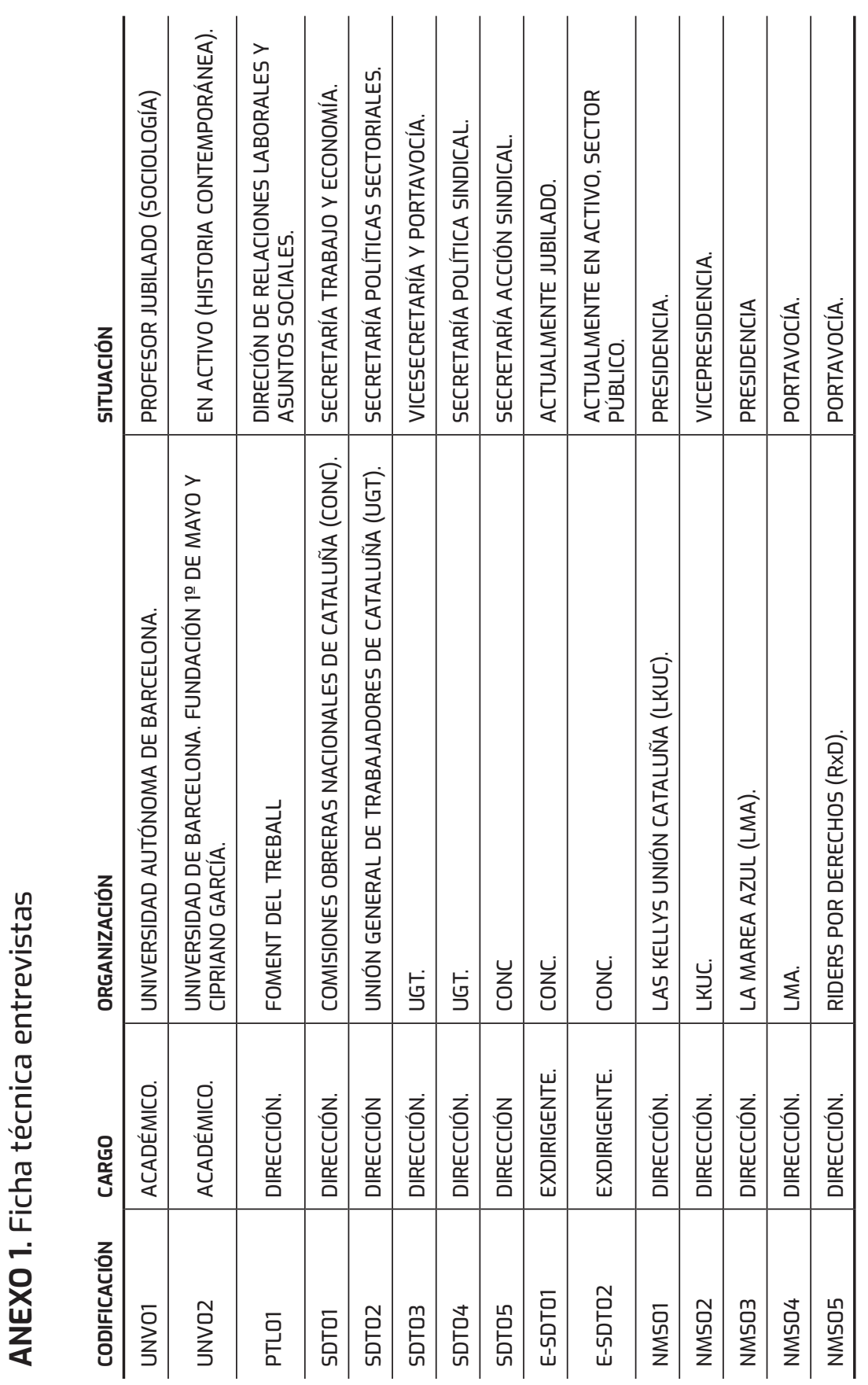

